\title{
KERATOME OR KNIFE INCISION FOR CATARACT* ASSESSMENT OF 180 CASES
}

\author{
BY \\ HOWARD REED \\ Department of Ophthalmology, Winnipeg Clinic, Winnipeg, Manitoba
}

DAVIEL (1753) described the first satisfactory method of cataract extraction before the Academie Royale de Chirurgie in 1752. He opened the eye with an instrument similar to the modern keratome and enlarged the incision with scissors. This method gradually displaced the ancient practice of couching until von Graefe described his cataract knife for making the incision in 1865. Von Graefe's cataract knife then remained in common use until about 10 years ago when the keratome began to regain favour. In America the keratome is now the most popular instrument, but in England the cataract knife is still in most common use.

The incision is one of the biggest factors in performing a successful extraction, and it is important to try to determine which is the better method. This series of extractions was planned in an attempt to assess the relative value of using the keratome or the cataract knife for this purpose. A few series have been reported in which the results of each type of operation performed by a number of operators have been compared (Davis, 1950; Randolph and Eareckson, 1953), but this is not satisfactory because it does not eliminate the varying skills of the different operators. The skill of the operator may be a bigger factor than the type of incision used.

In this series all the operations were performed by the author and ail cataract extractions performed during the period under review have been included. In an attempt to eliminate all possible variables the two methods were used alternately. This routine was broken only when operating upon the second eye of a patient when the alternative method of incision was used. In this consecutive series of 180 cataract extractions ninety were made with a cataract knife and ninety with the keratome and scissors.

I intended at first to use no sutures, because a bad section can be firmly closed by accurate corneoscleral suturing and a good section can be made to gape by faulty sutures. In the first 82 cases in this series, I used conjunctival sutures in four cases only, but in the last 98 cases the conjunctival flap was closed with three or four silk sutures. No corneoscleral sutures were used because I considered they would influence the comparison of the two types of incision.

*Received for publication January 1, 1955. 


\section{Technique}

Novocaine was injected into the facial nerve, within the rectus muscle cone, into the superior rectus, and upper and lower lids. Lid sutures and a superior rectus stitch were used. General anaesthesia was used in a few cases only.

Iridectomy.-Although a round pupil is preferable to a "key-hole" pupil, a full iridectomy was done in every case because to perform a peripheral iridectomy in some cases, a full iridectomy in others, and occasional peripheral iridotomies would introduce variable factors. Moreover, a full iridectomy is probably the best method of minimizing the risk of iris prolapse.

TABLE I

POSTOPERATIVE REFRACTION AT 3 MONTHS NOT POSSIBLE

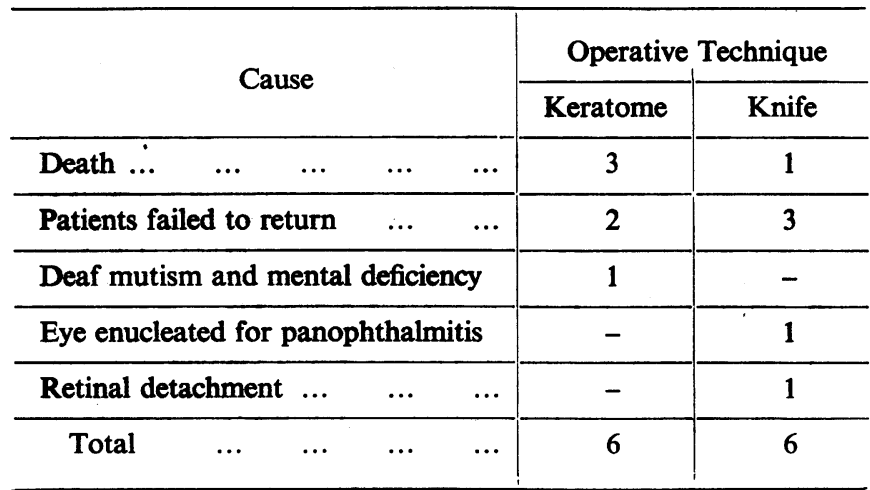

Extraction.-Mature lenses were removed by extracapsular extraction. Capsulectomy forceps were used and the extraction was followed by anterior chamber irrigation with normal saline. Immature and secondary cataracts were removed by intracapsular extraction with Arruga's forceps. Most hypermature lenses were delivered by intracapsular extraction. All cases were included whether

the capsule ruptured during intracapsular delivery or not. Capsulotomy was required at a later date in six cases only.

\section{Visual Results}

The crucial test of any cataract extraction is the corrected visual acuity. A postoperative refraction was not obtained in some cases (Table I).

Other patients had lesions present before operation (Table II).

When these cases are excluded, 64 keratome cases and 61 cataract knife cases remain for comparison. A corrected visual acuity of $6 / 6$ or $6 / 9$ is usually considered to be a successful result.
TABLE II

GOOD CORRECTED VISION COULD NOT BE EXPECTED BECAUSE OF ANOMALIES PRESENT BEFORE OPERATION

\begin{tabular}{|c|c|c|}
\hline \multirow{2}{*}{ Disease } & \multicolumn{2}{|c|}{ Operative Technique } \\
\hline & Keratome & Knife \\
\hline Macular degeneration & 5 & 8 \\
\hline Myopic degeneration & 3 & 6 \\
\hline Diabetic retinopathy & 3 & 2 \\
\hline Long-standing glaucoma & 5 & 3 \\
\hline Tobacco amblyopia ... & - & 1 \\
\hline Interstitial keratitis $\ldots$ & 1 & 1 \\
\hline Corneal nobulae & 1 & 1 \\
\hline $\begin{array}{lll}\text { Old uveitis } \quad \ldots & \ldots\end{array}$ & - & 1 \\
\hline Rotinitis pirmentosa & 2 & - \\
\hline Total ... & 20 & 23 \\
\hline
\end{tabular}


The cases obtaining $6 / 6$ or $6 / 9$ by each method are shown in Table III.

TABLE III

COMPARISON OF KERATOME AND KNIFE CASES OBTAINING 6/6 OR 6/9 VISION

\begin{tabular}{|c|c|c|c|c|}
\hline Operative Technique & & Number of Cases & $\begin{array}{c}\text { Visual Acuity of } \\
6 / 6 \text { or } 6 / 9\end{array}$ & $\begin{array}{l}\text { Percentage } \\
\text { Success }\end{array}$ \\
\hline Keratome and scissors & $\ldots$ & 64 & 58 & 91 \\
\hline Knife ... & $\ldots$ & 61 & 58 & 95 \\
\hline
\end{tabular}

The reasons for failure to obtain $6 / 9$ vision are given in Table IV. Three patients were unable to see better than 6/12 for no apparent reason. All the cases of vitreous haemorrhage were accompanied by total hyphaema.

TABLE IV

COMPLICATIONS CAUSING DEFECTIVE VISION

\begin{tabular}{|c|c|c|c|c|c|c|c|c|}
\hline \multirow{2}{*}{\multicolumn{7}{|c|}{ Disease }} & \multicolumn{2}{|c|}{ Operative Technique } \\
\hline & & & & & & & \multirow{2}{*}{$\begin{array}{c}\text { Keratome } \\
1\end{array}$} & \multirow{2}{*}{$\begin{array}{c}\text { Knife } \\
-\end{array}$} \\
\hline Postoperative uveitis & $\ldots$ & $\ldots$ & $\ldots$ & $\ldots$ & $\ldots$ & $\ldots$ & & \\
\hline Vitreous haemorrhag & $\mathrm{h}$ del & $\mathrm{d}$ at & rptio & $\ldots$ & $\ldots$ & $\ldots$ & 3 & 2 \\
\hline
\end{tabular}

Twenty-seven patients had a cataract removed from both eyes. The results are given in Table $\mathrm{V}$.

Five patients obtained a corrected visual acuity of less than 6/9 in one or both eyes. Two of these had bilateral macular degeneration and two bilateral diabetic retinopathy. The fifth patient was seen 3 weeks after the second extraction when a corrected vision of $6 / 12$ was recorded. She was not seen again because she fractured her femur and died before a final refraction could be done.

It is obvious from these findings that the method of making the incision has no significant effect upon corrected visual acuity.

TABLE V

RESULTS OF BILATERAL OPERATION

\begin{tabular}{c|c|c}
\hline \multirow{2}{*}{ Visual Acuity } & \multicolumn{2}{|c}{ Operative Technique } \\
\cline { 2 - 3 } & Keratome & Knife \\
\hline $6 / 6$ & 10 & 8 \\
\hline $6 / 9$ & 12 & 16 \\
\hline $6 / 12$ & 1 & 2 \\
\hline $6 / 18$ & 4 & 0 \\
\hline $6 / 24$ & 0 & 1 \\
\hline
\end{tabular}

Indications of Defective Wound Healing (Table VI)

(a) Postoperative Astigmatism.-A high degree of postoperative astigmatism is usually due to some gaping of the wound even when covered by a conjunctival flap. It was therefore considered best for purposes of comparison to calculate the average postoperative cylinder only in those cases in which it was less than $4 \mathrm{D}$ and to record the numbers of cases with more than $4 \mathrm{D}$ astigmatism separately.

The keratome and scissors incision therefore caused less postoperative astig- 
matism than did the cataract knife. When the knife incision was used the conjunctival flap was made with the cataract knife when cutting out, and therefore covered the wound adequately only in its middle third. When the keratome and scissors incision was used the conjunctival flap was prepared first so that the flap covered the whole length of the incision. This would appear to be the reason for less postoperative astigmatism after the use of the keratome.

(b) Delayed Anterior Chamber Formation.-Only when reformation of the anterior chamber was delayed for 5 days or more was it recorded. The one cataract knife case and three of the keratome and scissors cases were associated with choroidal detachments.

(c) Choroidal Detachment.-It is probable that many cases with choroidal detachment were overlooked because the periphery of the fundus was not thoroughly examined until the third week unless an untoward incident such as delayed anterior chamber formation occurred.

In one case only did the choroidal detachment persist. The anterior chamber had reformed normally, but 10 days after operation by the keratome and scissors method the patient had a nightmare and struck his own eye. The anterior chamber was lost, and a large bi-lobed choroidal detachment developed, and this condition persisted. The patient had been suffering from glaucoma for some years.

(d) Gaping of Wound under Conjunctival Flap or Bulging of Conjunctival Flap.This was not recorded unless it persisted until the seventh day. No serious cases requiring suturing were encountered.

(e) Filtering Scar.-This was noted when a small bleb was found at postoperative refraction 10 or 12 weeks after operation.

( $f$ ) Adhesion of Iris to Wound.-This was recorded when some elevation of the pupil was observed at postoperative refraction. It was presumably due to one or both pillars of the iris coloboma being caught in the wound.

(g) Iris Prolapse.-The keratome and scissors case which developed iris prolapse occurred in a mentally defective deaf mute intolerant of restraint.

These cases are all summarized in Table VI.

TABLE VI

CASES OF DEFECTIVE WOUND HEALING

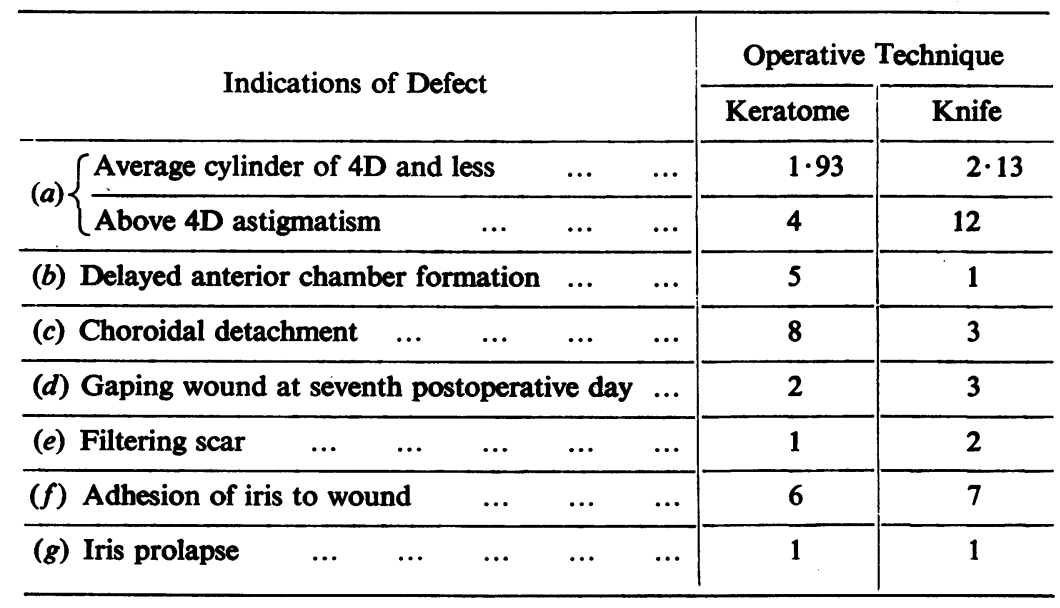




\section{Other Postoperative Complications}

Blood found in the anterior chamber at the first dressing on the day after operation is usually the result of the operation itself. When bleeding occurs after the first dressing, the blood is usually derived from newly formed capillaries bridging the wound. Only those cases in which bleeding occurred after the first dressing are included in Table VII.

TABLE VII

INCIDENCE OF HYPHAEMA

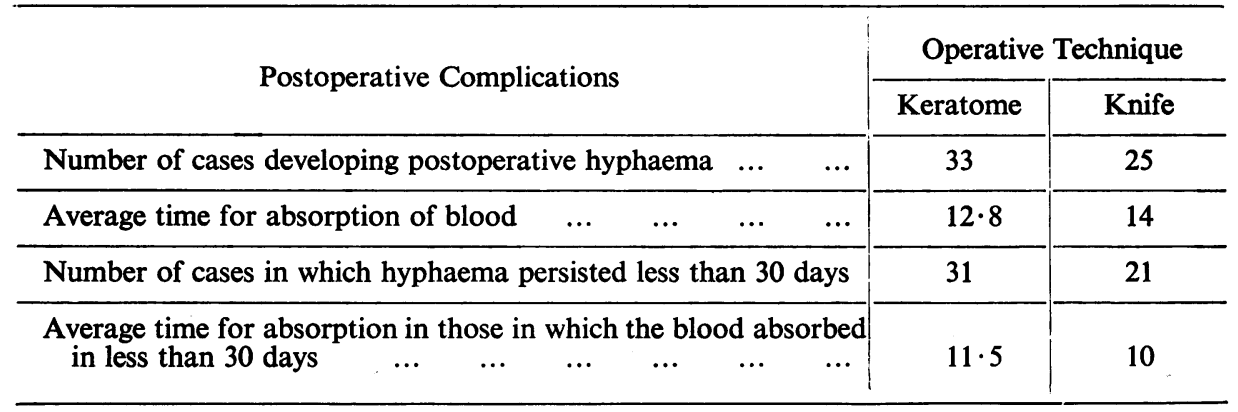

There were a few cases in which a full hyphaema occurred and took 30 days or more to absorb, and in all but one of them there was a definite or suggestive history of direct trauma. These were excluded in a second calculation and the findings recorded separately.

In this series diabetes was not a factor in causing hyphaema (Table VIII).

TABLE VIII

HYPHAEMA IN DIABETIC PATIENTS

\begin{tabular}{cc|c|c|c}
\hline \multicolumn{2}{c|}{ Patients } & $\begin{array}{c}\text { Number developing } \\
\text { Hyphaema }\end{array}$ & $\begin{array}{c}\text { Number without } \\
\text { Hyphaema }\end{array}$ & $\begin{array}{c}\text { Percentage developing } \\
\text { Hyphaema }\end{array}$ \\
\hline Diabetic $\quad \ldots$ & $\cdots$ & 2 & 8 & 20 \\
\hline Non-diabetic $\ldots$ & $\cdots$ & 56 & 114 & 33 \\
\hline
\end{tabular}

Table IX suggests that a raised blood pressure increases the risk of postoperative bleeding, because the average systolic and diastolic pressures in the group which developed hyphaema is higher than the average in the hyphaema-free group.

The average blood pressure in the cataract knife hyphaema group is higher than the corresponding keratome and scissors group. It may be, therefore, that hypertension played a part in causing bleeding and thus increasing the number of knife cases in which hyphaema occurred. 
The incidence of hyphaema bears no relation to age (Table IX).

TABLE IX

HYPHAEMA, BLOOD PRESSURE, AND AGE

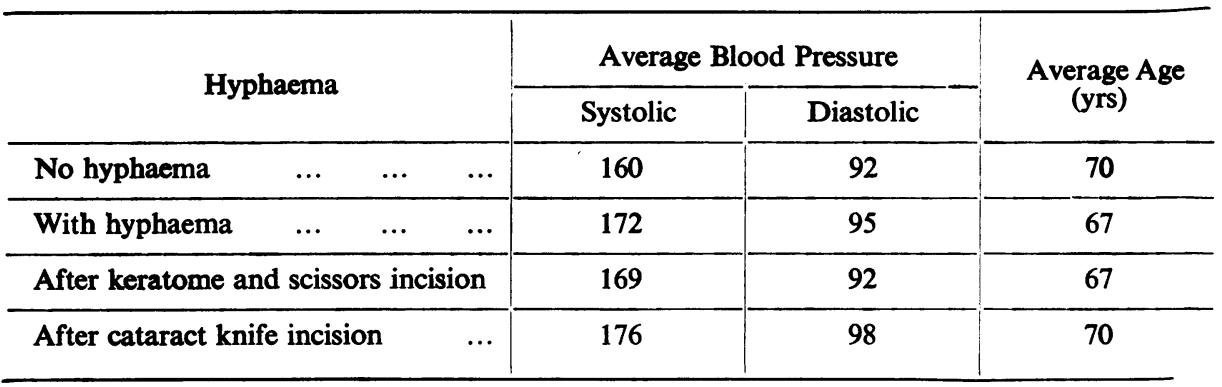

\section{Period of Hospitalization}

Patients were kept in hospital until the incision was firmly healed, all blood in the anterior chamber absorbed, and the eye white. Since keratome and scissors incisions involve a greater incidence of postoperative hyphaema and striate keratitis, it is to be expected that a slightly longer stay in hospital would usually be required. This was found to be so. Cataract knife patients were in hospital for an average of 18 days, and those operated upon by the keratome and scissors method were in hospital for an average of 19 days.

\section{Discussion}

(a) Comparison of Wound Healing in other Reported Series.-Davis (1950) found that delayed anterior chamber formation, gaping wound, prolapse of iris, and choroidal detachment were more frequent after keratome and scissors incision. Later complications, such as filtering scars, incarceration of iris, and secondary glaucoma, were also more common in his series. Randolph and Eareckson (1953) found no significant difference in complications indicative of defective wound healing. In the present investigation, also, both methods appeared to be equally satisfactory from this point of view. It should be noted, however, that Davis was reviewing a considerably larger number of cases.

(b) Postoperative Hyphaema.-The hyphaema rate in the whole series is high; it occurred in approximately one-third of the cases. Hughes and Owens (1945), in their review of some 2,000 cases, found that hyphaema occurred most frequently in the type of operation used in most of the cases in this series, i.e. the combined intracapsular extraction with conjunctival sutures. In fact, their figures, and those of Leech and Sugar (1939) suggest that the use of conjunctival sutures actually increases the incidence of postoperative hyphaema. This observation is corroborated by the present findings (Table $\mathrm{X}$ ).

When conjunctival sutures are used there is a tendency to take a good bite of the tissue in an attempt to close the incision firmly. The fiap is therefore 
TABLE $X$

HYPHAEMA AND USE OF SUTURES

\begin{tabular}{|c|c|c|c|c|}
\hline \multirow{2}{*}{\multicolumn{2}{|c|}{ Sutures }} & \multirow{2}{*}{$\begin{array}{l}\text { No. of } \\
\text { Operations }\end{array}$} & \multicolumn{2}{|c|}{ Hyphaema } \\
\hline & & & Cases & Percentage \\
\hline None used $\quad \ldots$ & $\ldots$ & 78 & 21 & 27 \\
\hline Conjunctival only & $\ldots$ & 102 & 37 & 36 \\
\hline
\end{tabular}

under tension. When any stress occurs to cause gaping of the wound, new blood vessels passing to a conjunctival flap under tension are more likely to rupture than those passing to a loose unsutured flap. Corneoscleral sutures which pass through rigid tissue and hold the wound edges firmly together would theoretically be more effective in preventing postoperative haemorrhage and this is confirmed by the reported results (Hughes and Owens, 1945; Leech and Sugar, 1939; McLean, 1940; Bell, 1949).

In the present investigation postoperative bleeding was more frequent after a keratome and scissors incision than after a cataract knife incision. Davis (1950) and Randolph and Eareckson (1953) found the same.

(c) Striate Keratitis (Table XI).-Folds in Descemet's membrane or striate keratitis were seen in 48 cases after the keratome and scissors incision and in seventeen cases after the cataract knife incision. The appearance and severity of this condition seem to vary directly with the amount of manipulation of the cornea. When enlarging each extremity of the keratome incision with scissors each snip necessitates raising the corneal flap to insert the blade of the scissors, and these manipulations seem to cause the condition to occur so frequently with this type of incision. Fortunately, it has no deleterious effect upon the postoperative visual acuity, but there is no doubt that the use of keratome and scissors causes more inflammation and irritability than the cataract knife.

(d) Vitreous Loss (Table XI).-Since this complication occurs at the time of the extraction of the lens it is no test of the relative merits of each incision.

TABLE XI

OTHER POSTOPERATIVE COMPLICATIONS

\begin{tabular}{|c|c|c|c|c|c|c|c|c|}
\hline \multirow{2}{*}{\multicolumn{7}{|c|}{ Complication }} & \multicolumn{2}{|c|}{ Operative Technique } \\
\hline & & & & & & & Keratome & Knife \\
\hline Striate keratitis & $\ldots$ & $\ldots$ & $\cdots$ & $\cdots$ & $\ldots$ & $\ldots$ & 48 & 17 \\
\hline Vitreous loss $\ldots$ & $\ldots$ & $\ldots$ & $\ldots$ & $\ldots$ & $\ldots$ & $\ldots$ & 5 & 4 \\
\hline
\end{tabular}

(e) Operative Aspects of Each Method.-The cataract knife section may be performed more quickly than the keratome incision, but this is not a valid 
argument in its favour in these days of adequate local and general anaesthesia. Some operators, especially those who operate relatively infrequently, never have confidence in their ability to make a good section with the cataract knife. For these the keratome and scissors method is probably better because less skill is required. But it is not without draw-backs, for it tends to cause a jagged wound and the snips with the scissors are made in the absence of an anterior chamber so that there is more risk of damaging the iris.

It is often argued that the repeated insertion of the tips of the scissors into the wound when making a keratome and scissors incision increases the risk of infection. In this connexion it is interesting that in this series the only patient who developed postoperative panophthalmitis was one in whom the incision was made with a cataract knife.

In this case a $48-\mathrm{hr}$ culture of the conjunctival sac just before operation was negative, the tear ducts were patent, and no septic foci were found either before or after the development of the panophthalmitis. It was the second of three cataracts operated upon consecutively during the same operating list, and was the only one to become infected. A virulent infection occurred and the eye perforated on the fourth day after operation. Colonies of Staphylococcus aureus were cultured from the pus. In this case the incision had been made with a cataract knife whereas the keratome and scissors had been used for the first and third cases.

Although one case has no significance, the argument that the use of keratome and scissors increases the risk of infection gains no support from this incident.

( $f$ ) Other Factors requiring Investigation.-Two other inter-related factors which enter into this problem of keratome and scissors versus cataract knife have not been solved by the present investigation:

(i) Wound Healing (Dunnington, 1951; Reed, 1954). Samuels (1952) has shown that vertical corneal wounds gape internally more than oblique wounds. It is probable that the average keratome and scissors incision is more perpendicular to the surface of the cornea than the average cataract knife incision. If this is so, it would tend to gape internally. This has not yet been proved, but it is an important factor which deserves investigation.

(ii) Corneoscleral Sutures.-Although none were used in this investigation, it has been shown repeatedly that corneoscleral sutures aid wound healing and decrease the incidence of postoperative complications (Davis, 1950; Hughes and Owens, 1945; Leech and Sugar, 1939; McLean, 1940; Bell, 1949). Some surgeons prefer preplaced and others postplaced corneoscleral sutures. Postplaced sutures may be used with equal facility with each method of incision, but when a number of preplaced corneoscleral sutures are inserted it is easier to avoid cutting them if keratome and scissors are used. The insertion of three or four such sutures, however, makes for a prolonged operation and a red irritable eye. There appears to be no doubt that some form of corneoscleral suturing is desirable, but the ideal number and type of suture and whether it is best to use silk or catgut have yet to be decided. 


\section{Conclusions}

(1) There was no significant difference in the visual results obtained by either method.

(2) In this series there appeared to be no significant difference in wound healing; indications of poor wound healing, such as gaping of the wound, filtering scar formation, incarceration of iris, and iris prolapse, occurred about equally in each group. Postoperative astigmatism was less in the keratome and scissors group. It is suggested that this was due to the fact that in this method a conjunctival flap covers the whole length of the incision. On the other hand, reformation of the anterior chamber was seriously delayed in five keratome and scissors cases but in one cataract knife case only.

(3) Striate keratitis and postoperative hyphaema were more common after the keratome and scissors incision. The eyes therefore tended to remain congested and irritable for a longer period and stay in hospital was prolonged.

(4) As a result of this investigation it has been impossible to conclude that one method is better than the other. It seems that it remains a question of personal preference and skill.

\section{Summary}

A consecutive series of 180 cataract extractions, ninety performed by the keratome and scissors method and ninety by the cataract knife method, is reported. Each method was used alternately. When the results of the two groups were compared, no significant difference was found, and it was concluded that the choice of method is a matter of individual preference. The problems of wound healing and of the association of each method of incision with various types of corneoscleral suturing have yet to be thoroughly assessed.

My thanks are due to Professor Arnold Sorsby for guidance in the conduct and presentation of this investigation, and to Sister Thorogood and the Staff of the Royal Eye Unit, Lambeth Hospital, London, where most of this work was done.

\section{REFERENCES}

Bell, D. P. (1949). Amer. J. Ophthal., 32, 639.

Daviel, J. (1753). Mém. Acad. Chir. (Paris), 2, 337.

Davis, F. A. (1950). Arch. Ophthal. (Chicago), 44, 175.

DunNington, J. H. (1951). Amer. J. Ophthal., 34, 36.

Graefe, A. VON (1865). v. Graefes Arch Ophthal., 11, pt 3, p. 1.

Hughes, W. F., JR., and Owens, W. C. (1945). Trans. Amer. Acad. Ophthal. Otolaryng, 49, 251.

LeECH, V. M., and Sugar, H. S. (1939). Arch. Ophthal. (Chicago), 21, 966.

McLean, J. M. (1940). Ibid., 23, 554.

RANDOLPH, M. E., and EARECKSON, V. O. (1953). Amer. J. Ophthal., 36, 350.

REeD, H. (1954). In "Modern Trends in Ophthalmology ", ed. A. Sorsby, 3rd series, pp.288-290. Butterworth, London.

SAmuels, B. (1952). Trans. ophthal. Soc. U.K., 72, 327. 